\title{
DETERMINATION OF REPRESENTATIVE LOADING CONDITIONS FOR EFFECTIVE SEMITRAILER DESIGN
}

\author{
Karel Kural ${ }^{1}$, Mark Voskuijl ${ }^{2}$, Tian Fengnian ${ }^{2}$, Joop Pauwelussen ${ }^{1}$ \\ ${ }^{1}$ HAN Automotive Research, HAN University of Applied Sciences, Arnhem, The Netherlands \\ ${ }^{2}$ Flight Performance and Propulsion Group, Faculty of Aerospace Engineering, \\ Delft University of Technology, Delft, The Netherlands
}

Submitted 10 June 2013; resubmitted 27 August 2013, 23 September 2013; accepted 22 October 2013

\begin{abstract}
Obtaining a representative loading spectrum that corresponds well to the reality is still one of the greatest challenges for fatigue life calculations and optimal design of the trailer body. A good qualitative and quantitative knowledge of the spectrum leads to more efficient usage of material, a better design of connection points and an overall decrease of the weight of the trailer, which finally results in a significant decrease in the price of a ton of cargo per $\mathrm{km}$. Despite that, the approach is nowadays mostly based on the experience and rules of thumb. It typically results in over-dimensioning of some parts while other parts remain vulnerable to failure due to unknown loading patterns. This paper describes a generic approach to solve the problems mentioned above applied in a research project named FORWARD (Fuel Optimized trailer Referring to Well Assessed Realistic Design loads). The project lasted two years and was carried out in cooperation with several different trailer manufacturers and 1st tier suppliers. The loading history of more than 1000 hours for five trailer types were captured in the shape of strains, accelerations and velocities of various elements of the trailers, enabling reconstruction of the loading in terms of forces and moments acting on the wheels and kingpin. Parallel to this extensive test-campaign, a novel generic physics-based computational approach was developed to predict selected loads encountered during common manoeuvres to all trailer types. The computational approach was validated against test-data and resulted in creating a generic multibody library applicable for all trailer types, and an automated post-processing routine for the large amount of test-data.
\end{abstract}

Keywords: loading his tory; trailer; simulation; modelling; testing; 3D dynamics model; durability.

\section{Introduction}

In the past decades, the trailer industry has not been as progressive and dynamic as the civil car industry. Nowadays, the trailer industry can be divided into two main groups. The first group consists of large enterprises producing more than 100 trailers a week and aiming to satisfy the mainstream demand of the market. The second group consists of all manufacturers with a production rate significantly lower than 100 trailers per week and aiming to produce more customized trailers. It is clear that especially for this second group it is complicated to invest in the research and development due to a limited budget. Trailers are, therefore, commonly designed by small companies using traditional conservative methods that make use of conventional materials and techniques. Traditional methods do not provide accurate design loads and as a result, some structural components are usually oversized in terms of the weight. The vehicle weight has a direct effect on the tyre friction forces and thus on the fuel con- sumption. Over the past years there has been an increasing pressure from the society to reduce $\mathrm{CO}_{2}$ emissions in the transport sector. In addition fuel prices are rising. This has stimulated logistic companies, which make extensive use of trailers, to minimize fuel consumption. As a result, the trailer industry was urged by the logistics companies to come up with more lightweight trailer designs. This can only be achieved when realistic design loads are available, allowing accurate fatigue calculations on critical components in the trailer structure. The need for such a 'fatigue-design' approach is also stressed by Morel et al. (2010). Therefore, HAN University of Applied Sciences and the Dutch Chassis and Bodywork association FOCWA (http://www.focwa.nl, gathering all Dutch trailer manufacturers), based on previous co-operation, started up a project under the name FORWARD (Fuel Optimized trailer Referring to Well Assessed Realistic Design loads) to support small and medium trailer manufacturers. The project includes seven trailer manu- 
facturers, two 1st tier suppliers (axles and suspension components) and four research institutes. The portfolio of trailers is listed in Table 1 . One can see a rather large diversity of overall length, weight as well as the purpose of use of the trailer, which obviously implies different operational conditions.

Table 1. Trailers used in the project

\begin{tabular}{llccl}
\hline $\begin{array}{l}\text { No } \\
(\#)\end{array}$ & Trailer type & $\begin{array}{c}\text { Length } \\
{[\mathrm{m}]}\end{array}$ & $\begin{array}{c}\text { Empty } \\
\text { weight } \\
{[\mathrm{kg}]}\end{array}$ & \multicolumn{1}{c}{ Remarks } \\
\hline 1. & Potato trailer & 12.10 & 5300 & - \\
\hline 2. & $\begin{array}{l}\text { Liquid cargo } \\
\text { trailer }\end{array}$ & 10.25 & 8300 & $\begin{array}{l}\text { 1st and 3rd axle } \\
\text { steered }\end{array}$ \\
\hline 3. & Low loader & 19.85 & 16800 & All axle steer \\
\hline 4. & Double decker & 13.72 & 10750 & $\begin{array}{l}\text { Independent wheel } \\
\text { suspension }\end{array}$ \\
\hline 5. & Walking floor & 13.53 & 11450 & $\begin{array}{l}\text { 2nd and 3rd axle } \\
\text { steered }\end{array}$ \\
\hline trailer I & Walking floor & 13.53 & 7800 & \\
\hline trailer II & Livestock trailer & 13.69 & 13000 & 3rd axle steered \\
\hline
\end{tabular}

The main goal of the two year lasting project was to measure and identify real loading conditions of the trailer during everyday operation and to use these for calculation of the fatigue on critical components, enabling weight reduction by re-design of these components. The general process to achieve this objective can be summarized as follows. The loading conditions are translated into forces and moments acting on the wheels and kingpin, which in turn can be used for fatigue calculations by means of finite element analysis. Because the direct measurement of the forces during the operation is very difficult with the required accuracy it was decided to employ multibody dynamics vehicle models to translate measured vehicle states into the forces and moments as depicted in Fig. 1.

Since the multibody dynamics and Finite Element Method (FEM) models play an essential role, all models used were subjected to both qualitative and quantitative validation in order to ensure that the output corresponds well to reality. The validation was done in terms of special measurement routines, which cover the operational conditions and will be described later on.

An overview of previous research studies related to the general project strategy indicated in Fig. 1 is provided here. In general, vehicle dynamics models, based on multibody dynamics, are mainly used for suspension design (Sharp, Crolla 1987; Cao et al. 2011). The models

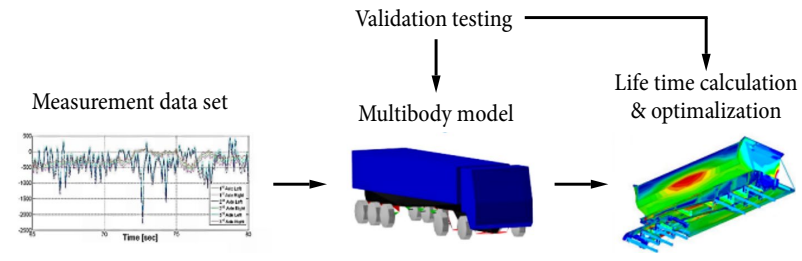

Fig. 1. General project strategy are then typically used to determine ride comfort, handling qualities and component loads (Falkner, Reinalter 2006). Fatigue calculations are typically not included in these design efforts. With the development of more complex (mechatronic) vehicles that include active control systems, there is a need for Multidisciplinary Design Optimization (MDO) where there is a seamless link between analysis tools allowing us to find the optimal design automatically (He, McPhee 2005). The necessity for an integrated engineering framework is also stressed by Zhang et al. (1999). This framework should produce accurate stress/strain results to enable fatigue life calculations. It is indicated that the conventional practice in industry is to use a linear static approach for fatigue life calculations. In this approach, unit loads are applied to certain structural components in order to obtain stress influence coefficients. These coefficients are multiplied with dynamic loading histories from test data or from multi (rigid) body analysis methods to predict fatigue life. Breytenbach and Els (2011) developed a framework to obtain optimal suspension characteristics in terms of structural fatigue life. To achieve this, a 7 degree of freedom dynamic vehicle model was used to calculate forces on the suspension. Empirical relations were used to calculate the resulting stress and damage to the suspension. Hence their framework relies heavily on experimental data of vehicle components. Gombor (2005) demonstrated the coupling of a Computer-Aided Design (CAD) model to a vehicle dynamics model using multibody dynamics and a FEM model to carry out dynamic analysis and fatigue calculations of a bus body frame. The focus of this study was on the required level of fidelity of FEM models in the simulation chain. Gombor (2005) further shows, that accurate fatigue calculations can already be performed of structural components in the design phase of the vehicle. The study is however limited to analysis of a single vehicle configuration and the operational real-life loading condition is not investigated in contrast with the current research study. Wang et al. (2008) describe a similar approach to predict the fatigue life of a shoulder pole beam in a heavy duty truck. Both the work of Lee et al. (1995) and Lin et al. (2006) show that fatigue analysis of suspension components can be performed accurately in a simulation framework when finite element models are available with a sufficient level of detail. This reduces the need for extensive testing and allows investigating fatigue aspects in suspension design already in the early design stages. Lee and Han (2009) successfully coupled a multibody dynamic vehicle model to a finite element model for a passenger car in order to obtain an accurate prediction of the vehicle's durability. Crosheck (2001) performed a study on the integration and test of the full vehicle durability of a telescopic handler. A design and analysis framework was developed that coupled a dynamic vehicle model to a finite element analysis and a fatigue analysis. It was demonstrated that the structural fatigue of the full vehicle can be accurately predicted. Furthermore, Crosheck (2001) indicates that the structural design can be optimized, taking into account fatigue, before a vehicle is actually produced. 
A method to perform fatigue calculations on a critical component of a train locomotive was presented by Dietz et al. (1998). In their work, an analysis framework was constructed by coupling a CAD model to a multibody system and, finally, to a FEM program. The stresses calculated by the FEM program are used to predict the fatigue lifetime of a railway bogie. Accurate results were achieved by integrating flexible bodies in the multibody system. The operational use of a train locomotive is however well defined, much more restricted and well understood, compared to the current investigation with various trailer types operated by different logistics companies. At Volvo, the dimensioning of the tank installation for a Volvo S80 was done completely in a virtual environment (Fermér et al. 1999). The design includes several spot-welds. In order to achieve this, results from a multibody dynamics simulation, modelled in ADAMS, were used as input for a finite element model. MSC.Fatigue was used to analyse the fatigue of sheet metal parts and spot-welds. The capabilities of MSC.Fatigue as a design tool for automotive components are described in detail by Bishop et al. (1995). It was demonstrated by Zeiler that design sensitivities of a fatigue performance index can be successfully used in a MDO framework for automotive applications (Zeiler 2002; Zeiler, Barkey 2001). The structural optimization performed by Zeiler included both vehicle ride qualities and fatigue performance as objectives. The work was conducted on a relatively simple nine degree of freedom model.

In all the research studies described above, the investigations are limited to a detailed model of a single vehicle configuration or a single component of a vehicle. The design optimization is limited to the structural sizing of a fixed configuration. Furthermore, in order to obtain accurate results with the different computer aided engineering approaches described above, it is essential to have a realistic representation of real-life loading conditions for the vehicle or component under investigation. The representativeness of the driving spectrum and thus the accuracy of the loading condition is not investigated in research studies described above.

Since the multibody dynamics models of vehicles, used in the current research study, have a relatively large calculation time and complexity, some measured signals were used for simplified estimation of the forces by analogical approach extensively described by Pauwelussen et al. (2010). The estimates were further synchronized with all measured data, including GPS position, and brought in the database graphical user interface. Thus the trailer manufacturer can easily approach the data and assess particular loading patterns which can be then more accurately handled by multibody model. This step is not included in the previous studies Gombor (2005), Wang et al. (2008), Dietz et al. (1998) described above.

In FEM models, an emphasis has been put on the current study concerning the selection of appropriate postprocessors that can deal with welds. The design process is a purely physics based approach once a typical driving spectrum is known for a particular trailer type. Therefore it can also be applied to the design of completely new trailers.

Two aspects of the current research study, presented in this paper are considered novel. The first aspect is the identification of real loading conditions for a variety of trailers by means of extensive measurements during real-life operation. The second aspect is the development of an intelligent software system that enables the automatic generation of multibody simulation models for a wide variety of trailer configurations. This function is considered essential in the conceptual and preliminary design stage for lightweight vehicles since the structural configuration of the vehicle does not have to be fixed during the design optimization. This provides more freedom to the designer, The approach even allows the design of completely new vehicle configurations.

The paper is structured as follows. First, in section 1 the instrumentation of the test vehicles and the associated challenges are discussed. Section 2 deals with the actual testing in the field and at the test track to obtain the real-life loading conditions and validation data. Subsequently in section 3 the approach of data processing is explained. The multibody vehicle simulation framework is described in Section 4 followed by section 5 where the results of the measurement are presented. The paper is concluded by latest section, which discusses the results and draws final conclusions.

\section{Instrumentation}

While selecting an appropriate instrumentation, several challenges must be solved. The goal is always to find a good trade-off between the amount of the captured data, and its quality, which basically depends on the sampling frequency, and number of signals to be measured.

Since the objective was to reconstruct the load history of the trailer, the focus was on selection of sensors, which enable to identify and quantify common operational events of the semitrailer such as braking, cornering or hitting the potholes. There was also focus on the sensors, which help to distinguish the current loading state of vehicle caused by the cargo. Lastly we aimed to link certain load patterns with particular roads thus GPS tracking device was needed.

It resulted into the following sensor categories; strain gauges, accelerometers, GPS, gyroscopes, potentiometers, ABS sensors, and pressure sensors. An overview of the sensors employed is presented in Fig. 2.

The next step was to select the sensors with corresponding resolution and reliability. As for the resolution, the accelerometers in particular needed to consider since the measurement ranges on sprung and unsprung mass can differ significantly. The reliability and robustness of the sensors at any atmospheric conditions was also essential because some of the test runs has been carried out during hazy winter time. To reduce installation time and operating costs we employed a multi-purpose sensor that enables measurement of acceleration as well as GPS, and rotational velocities (http://www.xsens.com). 
a)

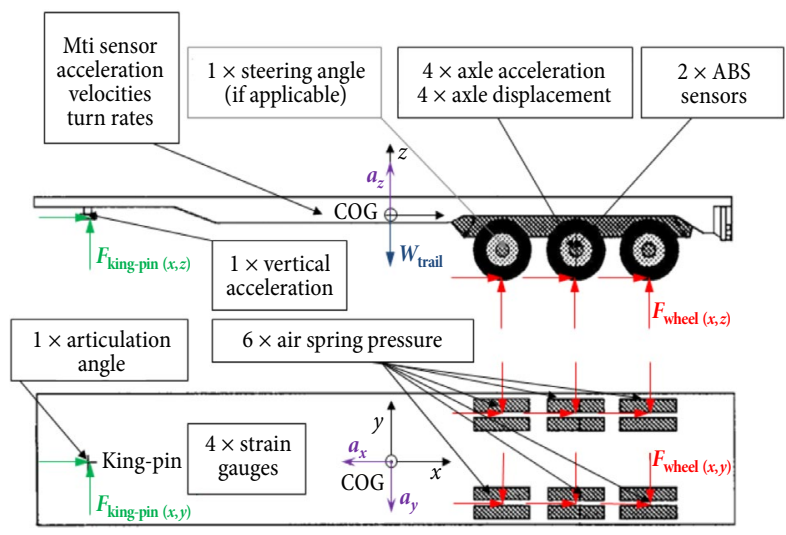

b)

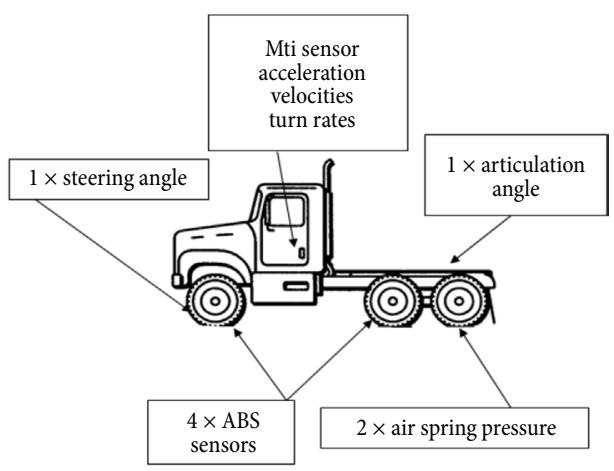

Fig. 2. Instrumentation for: a semitrailer (a) and for a tractor (b)

The last component of the instrumentation was a Data Acquisition System (DAS) with wiring ensuring its connection to the sensors. The arrangement was flexible and modular so the installation and placement of the sensors and DAS for each of individual semitrailers could be done in short time.

Apart from the measurement setup described above, a pair of wheel force transducers (Fig. 3.) was used for selected test routines on the 'walking floor trailer II'. The sensor (http://www.kistler.com) provided rather accurate information about the forces and moments in the tyre-road contact patch. The information was obtained from the set of the load cells built in the tyre rim and by means of the sensor internal algorithm subsequently recalculated to the forces.

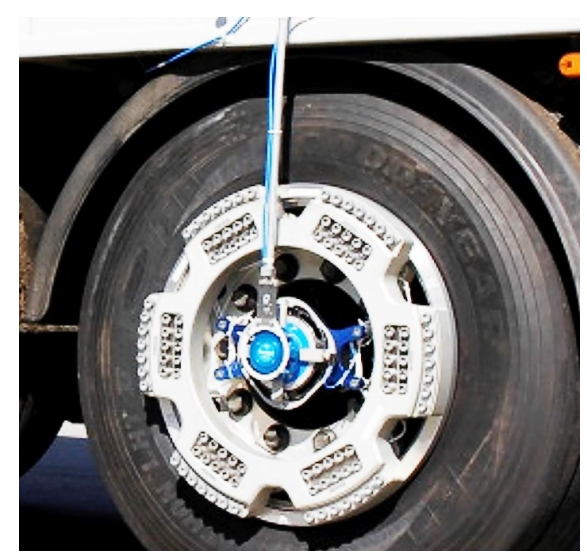

Fig. 3. Wheel force transducers

\section{Testing}

The testing for each of the semitrailers consisted of two parts. The effort aimed at obtaining sufficient data for validating the vehicle models, as described later on, and measurement of semitrailers during casual in-field operation. The tests followed each other chronologically. The validation testing lasted 2 days as the vehicle was tested in the empty and fully loaded state. The in-field measurement lasted for 3 to 4 weeks.

The validation testing was performed on a dedicated test track for commercial vehicles. The test procedure was identical for all the semitrailers and consisted of representative manoeuvres like lane changing, steady state cornering, braking, but also e.g. trespassing over the predefined obstacles to obtain sufficient input for vertical validation of the model. A special category of tests was dedicated to low-speed manoeuvring with high articulation angles (around 90 degrees) when the loading of the trailer structure is extreme. This manoeuvre is particularly useful for validation of the finite element structural models based on the strain gauge readings.

The in-field testing was very different for each of the trailers with respect to their diverse operational conditions. In general there were no restrictions and owners were asked to operate the vehicle as usual. Thus differences were observed in the loading patterns as well as used roads (example of the GPS tracking can be seen on Fig. 4).

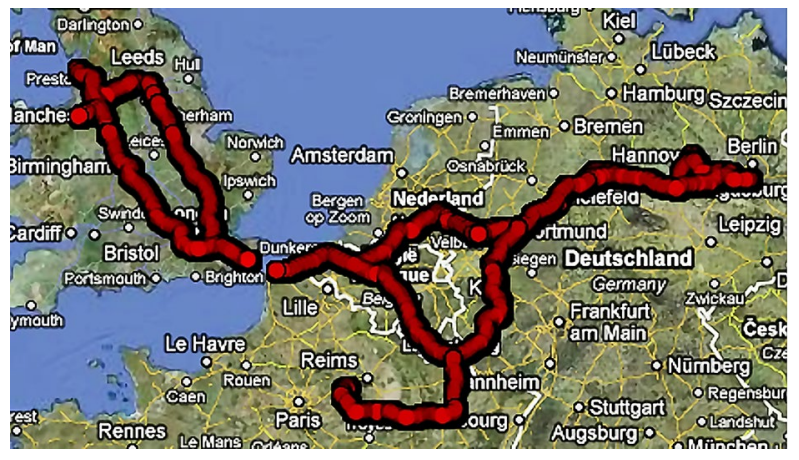

Fig. 4. Example of GPS semitrailer tracking

The file testing database has up till now gathered measurements from 6 different countries including Benelux countries, Germany, the United Kingdom and France. In total approximately $40000 \mathrm{~km}$ of road data has been collected over more than 1000 hours, which represents extensive information of nearly six months of full time trailer operation.

\section{Data Processing}

After collecting the field test data an approach had to be established that would be capable of expressing both the qualitative and quantitative loading pattern of the semitrailer. Four methods were identified, which can be further employed for semitrailer fatigue lifetime calculation. 
The objective of the first approach was to count the number of casual events during the operation that could be subsequently quantified by forces on the wheels and kingpin by the multibody model. The casual events to identify were the following:

- braking;

- accelerating;

- cornering left;

- cornering right;

- heaving up;

- heaving down.

Each of these events was also assessed with respect to its intensity. In other words one should see for example the difference between soft and moderate braking. The accelerations of the semitrailer body were employed to identify the event and assess its intensity. Longitudinal acceleration was used for braking/accelerating, lateral acceleration for cornering left/right and for heaving up/down, vertical acceleration was used.

The function of the event counting algorithm can be explained via three steps in the Fig. 5 and is generally applicable to the all directions of acceleration. First, the noise from the signal is being removed by means of a Butterworth filter. Different filter settings need to be applied for each acceleration direction due to different noise frequencies. In the second step the signal is being split in a positive and negative part by means of the saturation element, which helps to identify two events from one acceleration signal, for example left/right cornering. In the last step, the local maxima and minima of the signal are being identified. Further, the signal is simplified to a form where only the points in between the local extremes are considered. Finally the algorithm runs through the processed signal and counts the events between the zero line and maximums and assigns such an event to the appropriate bin (level). Each bin is prescribed by certain acceleration span as can be seen in Fig. 5b, which also illustrates the form of the output of this post processing step.

The next step was to determine the vertical loading spectrum of the semitrailer as a function of the time that is directly linked to the semitrailer utilization rate. The processed signals were in this case air spring pressures, which were measured for each wheel. By simplified approach it has been accounted that the air pressure inside the springs is directly proportional to the vertical tyre load. The algorithm finds maximal pressure during the period of field testing measurement (3-4 weeks), afterwards the number of bins is being evaluated based on this maximal pressure, while constant span of the one bin is 0.5 bar. Finally the percentage of the total measurement time is assigned to each of the bins as well as each of the wheels. Based on the total driving time, one can figure out how long a particular wheel was operating under corresponding vertical load.

The third algorithm is dealing with combined loading during field testing on a time base. It was desirable to identify how often the vehicle is loaded from two or more directions for example simultaneous cornering and braking. To observe it, all three accelerations, as measured on the semitrailer body, were processed together. As output one can imagine three dimensional matrix (cube), as depicted on the Fig. 6, where each of the edges represents one acceleration direction. Each of bins then stands for unique combination of the loading (longitudinal, lateral and vertical) being evaluated from the acceleration. Every bin was also assigned by percentile fraction of the total driving time when this unique loading pattern is present. It gave a fair qualitative understanding of the loading. a)
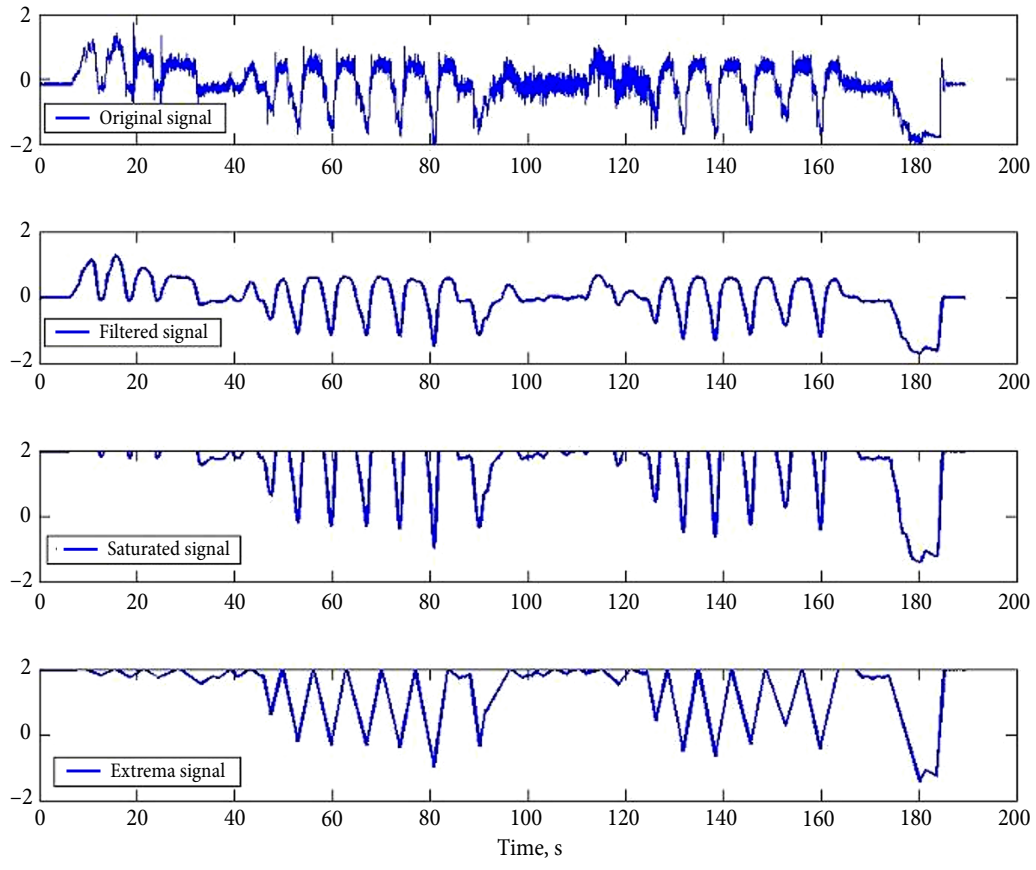

b)

\begin{tabular}{|l|c|}
\hline \multicolumn{1}{|c|}{ Event bin } & Number of counts \\
\hline LEVEL I & 77 \\
\hline LEVEL II & 0 \\
\hline LEVEL III & 2 \\
\hline LEVEL IV & 1 \\
\hline LEVEL V & 8 \\
\hline LEVEL VI & 2 \\
\hline LEVEL VII & 1 \\
\hline
\end{tabular}

Fig. 5. Acceleration signal: $\mathrm{a}$ - processing; $\mathrm{b}$ - output 


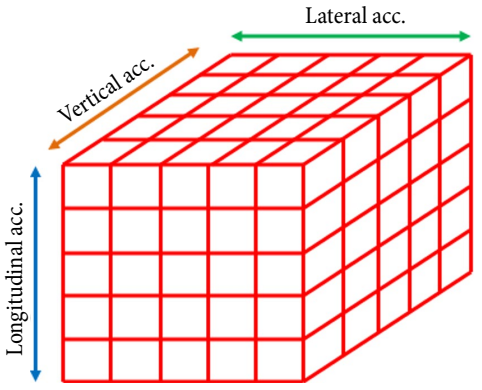

Fig. 6. Combined load matrix

The last post-processing method we employed was time sequence rain flow counting. The original approach of rain flow counting was developed by Matsuishi and Endo (1968) and is widely used for analyzing the fatigue data. The algorithm reduces the spectrum of varying load (stress, force...) history in time to the set of elementary reversals. The reversals are quantified through the mean value of the load, its amplitude and number of cycles in given regime. Each cycle has also sequence number which corresponds to the occurrence in original time history thus the cycles are being applied in the order which corresponds to reality. This approach was applied for post processing of the strain gauges data, which were placed on sensitive spots of the semitrailer such as corners or welds, however will not be discussed in this paper.

\section{Multibody Modelling}

The generic truck trailer multibody dynamics model for the simulation of realistic design loads is described in this section. The model, designated as FORWARDmodel, is intended to accurately predict the following key aspects:

- vehicle dynamics behaviour;

- dynamic loads.

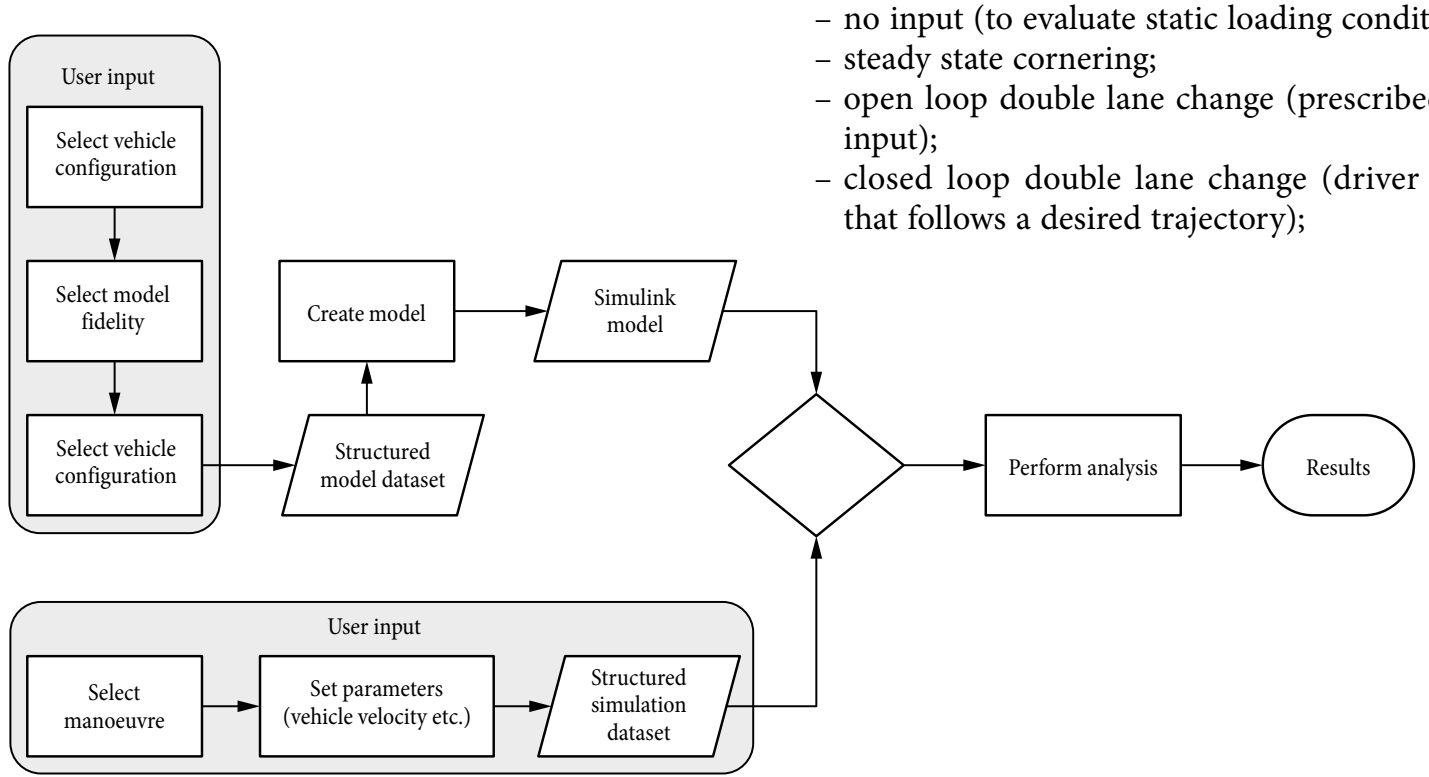

The FORWARD-model is designed to work with Matlab ${ }^{\circledR}$ and Simulink ${ }^{\circledR}$. Extensive use is made of the Simscape toolbox which allows the modelling of multidomain physical systems (http://www.mathworks.com). Simulation models of truck trailer combinations can be created and analysed in an automated fashion which makes it possible to integrate this tool in an automated design optimization framework. Furthermore, the automatic generation of simulation models significantly speeds up the development process of a new simulation model. The automatic model construction works as follows. All simulation models have an identical structure at the top-level. Various sub-models with different levels of fidelity are developed for each component of the simulation model. These sub-models are stored in a library. Each simulation model consists of the following main elements at the top-level:

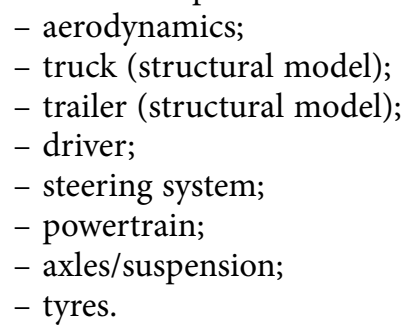

Even though the sub-models have varying levels of fidelity, they always have the same input and output vector. This is an essential feature for the intelligent software system that automatically creates the simulation model. The user only has to provide the vehicle configuration (e.g. number of axles, type of trailer etc.), the required modelling fidelity for each subsystem and the associated design parameters. Based on this input, the simulation model is constructed using the automatic model construction commands available in Matlab ${ }^{\circledR}$. This process is depicted in the Fig. 7.

As the simulation model has a fixed top-level structure, a standard set of manoeuvres can be executed automatically:

- no input (to evaluate static loading condition);

- steady state cornering; closed loop double lane change (driver model that follows a desired trajectory);

Fig. 7. Automatic model construction 
- straight acceleration and braking;

- straight driving on a low quality road;

- jacking/alley docking (trailer at 90 degrees relative to tractor);

- test data input (to simulate an actual test).

In order to give an impression of the available modelling fidelity, some specific modelling features are described in the section below.

A correct tyre model is essential for an accurate simulation of the vehicle dynamics and the prediction of dynamic loads (McCullough 2008). Use is therefore made of the well-known 'magic formula' model of Pacejka (2012). The TNO implementation of this model (TNO Automotive 2008) is applied in the FORWARDmodel. The tyre model is based on a large set of parameters. Several parameter sets are provided with the TNO implementation and the user of the FORWARD-model only has to specify the tyre radius. The user can also choose to provide a complete parameter set for a tyre if this information is available.

Both independent and solid axle suspension models are available in the tool. The most detailed suspension model consists of an air spring model, a shock absorber model, a leaf spring model and several connection elements representing the mechanism and thereby the kinematics. Both the shock absorber and air spring are nonlinear and adjustable models. To specify the detailed suspension model, the user should provide a range of parameters; the mass, stiffness and the compression and expansion limits of the air spring, the nonlinear damper characteristics as a function of damper velocity, and finally the masses of the leaf spring and shock absorber. If there is no information on a specific parameter, default values can be used in order to at least have a reasonable working model.

Five different trailer models are available:

- conventional;

- liquid cargo trailer;

- container;

- low loader;

- double-decker.

These trailer models consist of several rigid bodies connected with spring damper systems. The user has to specify the dimensions of the trailer, the locations of the axles and kingpin, the masses and inertias. If cargo is present in the trailer, each cargo element can be specified separately by its position, mass and inertia.

The liquid trailer is a special option which requires some more explanation. The crucial difference with a conventional trailer is the cargo. The liquid in a container which is not filled completely is free to move and will be affected by the motion of the vehicle. The motion of the vehicle is also affected by the motion of the liquid. A special model has therefore been developed to represent the dynamics of the liquid, commonly described as sloshing, as a mechanical system. A large amount of research has been done in this field in the past by NASA (Abramson 1966), since this phenomenon is quite important for space flight applications. The mechanical model for the liquid implemented in the FORWARD- model is based on reference (Dodge 2000). The mechanical model is a spring-mass model with one mass representing the moving liquid and one mass representing the section of the liquid which remains stationary. It is essential to select the correct spring stiffness and damping value for this system. Dodge (2000) provides an analytical solution for a cylindrical tank based on classical potential flow theory. This solution is implemented in the liquid trailer model. The motion of the liquid can actually make the vehicle tilt in some dynamic situations. This phenomenon was investigated previously by Badireddi (2007). The user input to the liquid trailer model consists of the type of liquid (petrol, milk, water, etc., each having a different density and viscosity), the dimensions of the cylindrical tank and the percentage by which it is filled.

In the closed loop simulation of the double lane change, a mathematical lateral driver model is enabled that tries to follow a predefined path. This mathematical model is in fact a relatively simple classical feedback control system defined by three parameters describing the driver behaviour (aggressiveness, preview distance and time delay). Various driver models can be found in the open literature and can easily be implemented in the FORWARD-model if desired. A good example is given by Chatzikomis and Spentzas (2009).

In this next section, a validation of the FORWARDmodel is performed. This specific model of a conventional trailer with three axles and no cargo consists of 49 rigid bodies. Overall there are 106 states that describe the condition of the vehicle. Other vehicle models may have more or less degrees of freedom, depending on the configuration. The FORWARD-model was validated against test data. Two example validation cases are displayed in Figs 8 and 9. The first validation demonstrates the ability of the tool to accurately predict the vehicle dynamics.
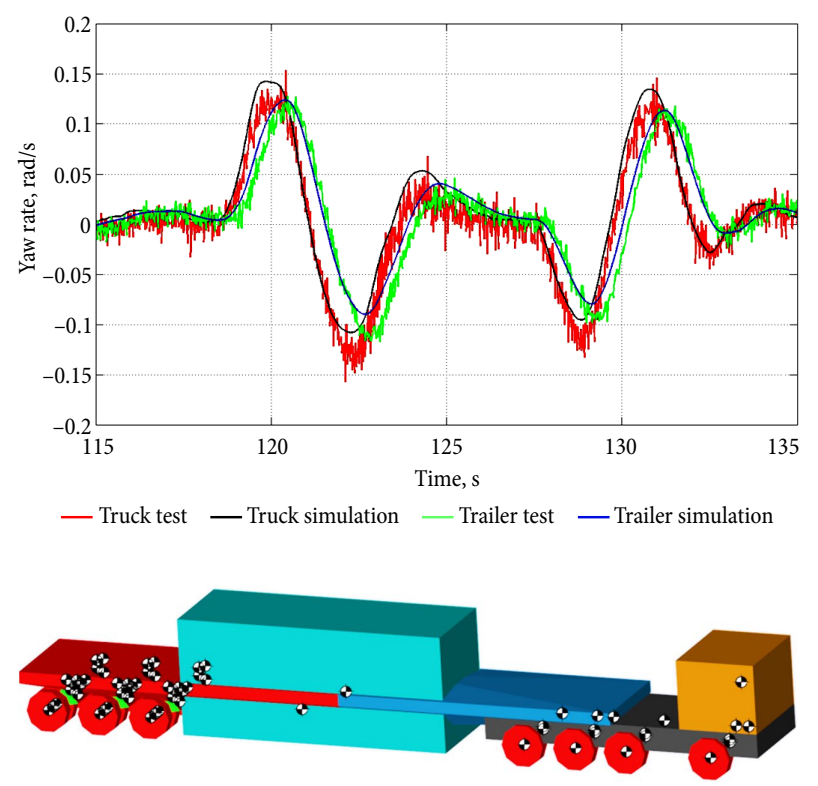

Fig. 8. Vehicle dynamics validation example 

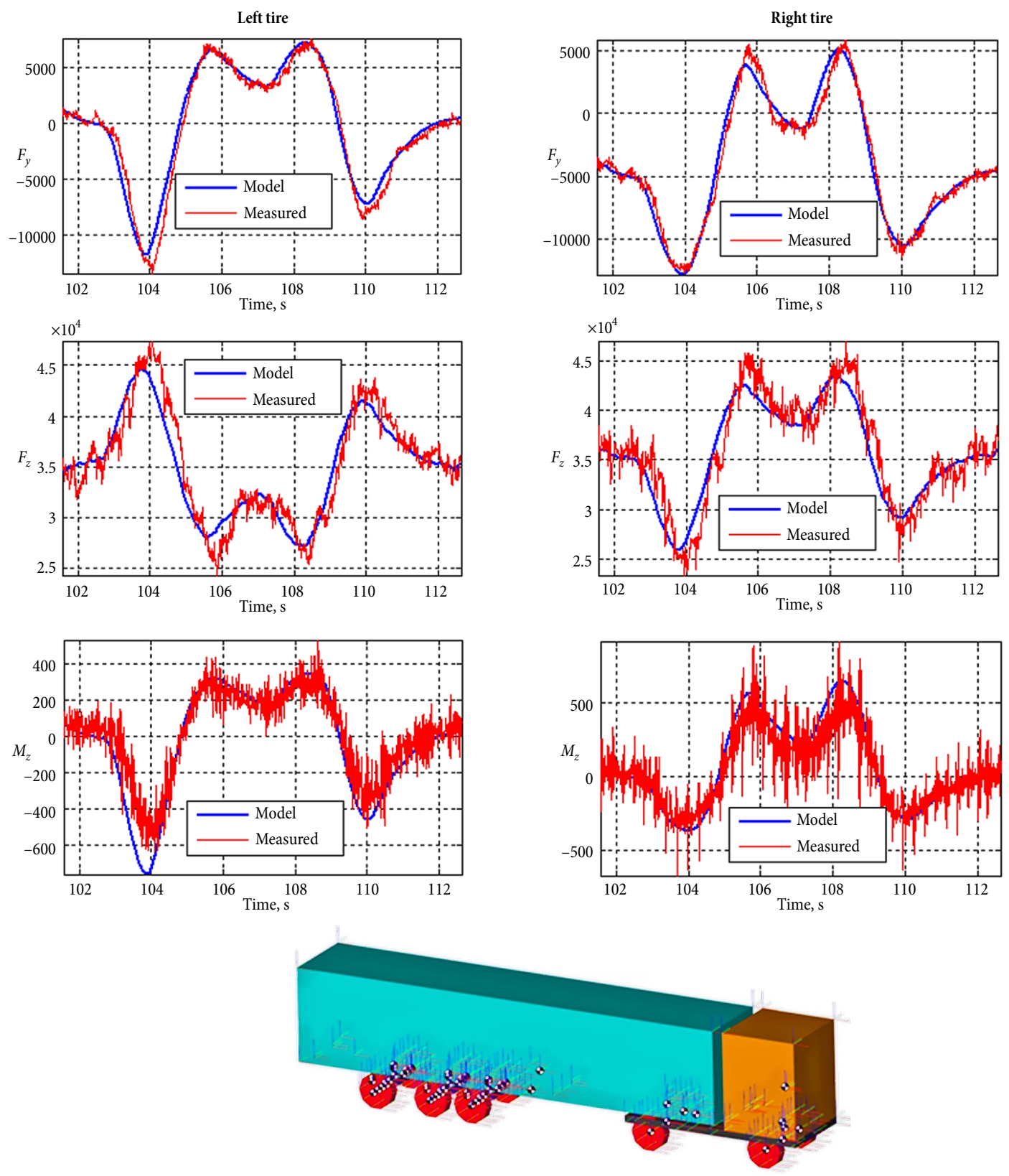

Fig. 9. Wheel forces validation during lane change

The yaw rate as a result of a double lane change manoeuvre is presented for a low loader trailer. It can be observed that both the simulated yaw rate of the truck and the simulated yaw rate of the trailer are in accordance with test results.

The second validation example demonstrates the ability of the simulation model to accurately predict the tyre forces and moments for a conventional trailer. Two wheels of the trailer where instrumented with wheel force transducers to allow direct measurement of forces and moments on the wheel. Fig. 9 shows that all forces and moments are accurately predicted by the simulation model. In addition, the results when the vehicle drives over a threshold are presented in Fig.10. The tyre vertical force and suspension travel closely match the simulation results. Forces and moments calculated by the FORWARD-tool can therefore be used as input for FEM models.

Finally, a simulation of a closed loop lane change is presented (Fig. 11). In this case, the simulation model follows a prescribed path. One can observe that the model tracks the path. The parameters describing the driver behaviour determine how well the simulation model follows the prescribed path. This example shows that the model can be used to simulate generic manoeuvres which are typically performed in operation.

In summary, the FORWARD-tool is validated against test data and can be used to accurately predict vehicle dynamics for selected vehicles. The effect of the vehicle loading and variation of particular dimensions can be simply investigated by means of the tool, but this analysis is beyond the scope of this work. Good example 

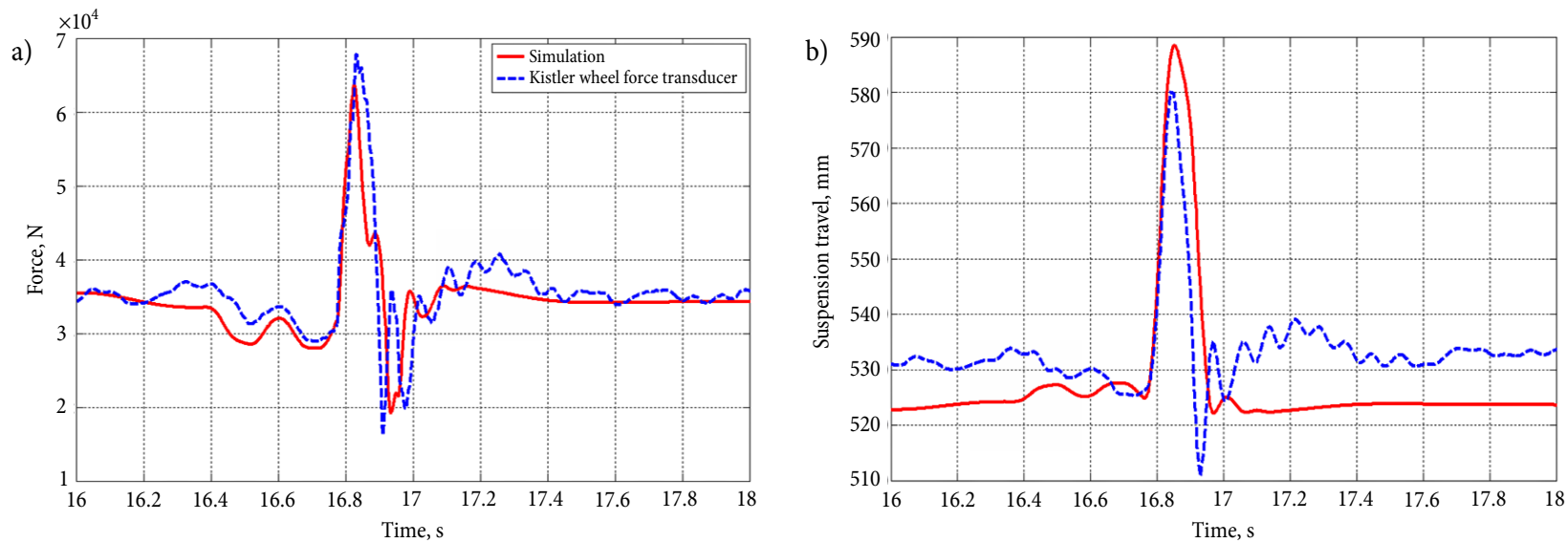

Fig. 10. Wheel forces validation when going over obstacle: a - tyre vertical force when going over the treshold; $\mathrm{b}$ - suspension travel when going over the treshold
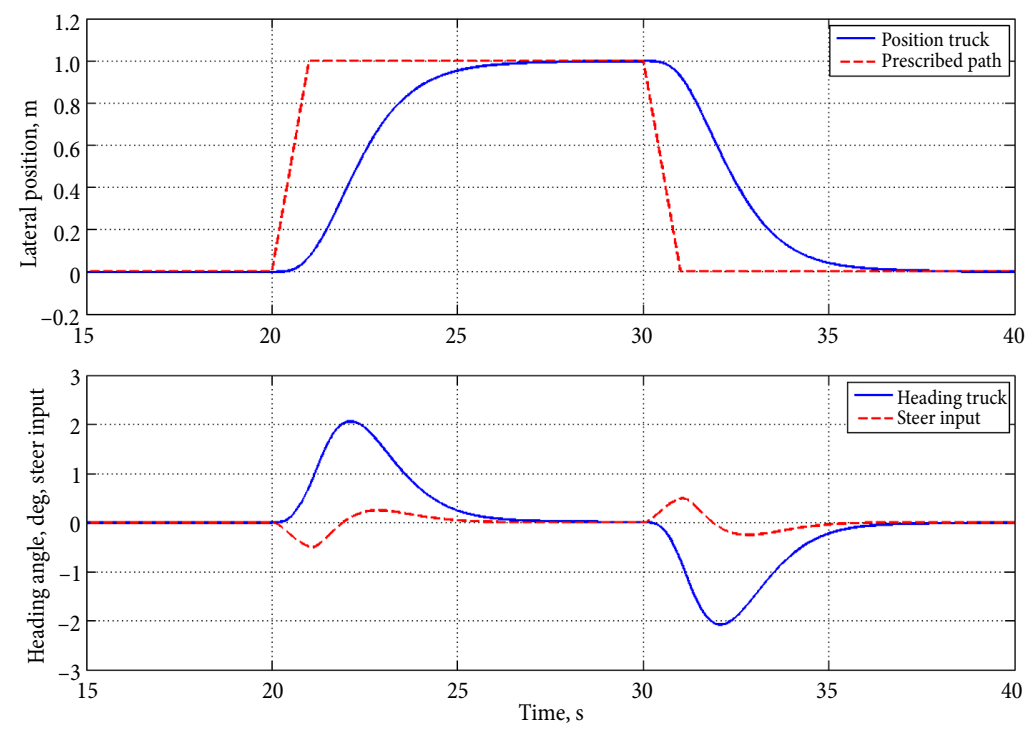

Fig. 11. Simulation of the closed loop double lane change

of sensitivity analysis for the commercial vehicle dynamics is however given by Kural et al. (2013). Furthermore a wide variety of trailer configurations can be created automatically, reducing model development time and allowing the simulation tool to be used in an automatic design framework.

\section{Results}

The measurement database gathers data obtained in 6 different countries from Western Europe covering both highways as well as public and rural roads. In total around forty thousand kilometres of the road data has been collected over more than one thousand operational hours. It represents approximately half year of full time semitrailer usage. The contributions from particular semitrailers can be seen in Fig. 12. The number above the line is the percentile fraction of the total measurement time and number bellow refers to the semitrailer type from Table 1 .

By processing the air spring pressures we aimed to identify the rate of the overloading and distinguish the loading modes with respect to the trailer type.

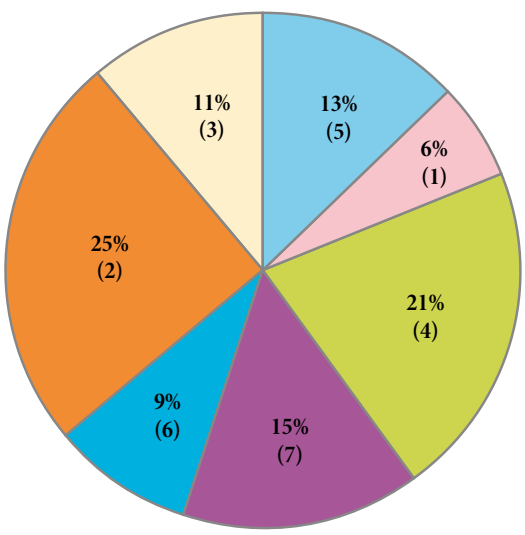

Fig. 12. Gathered data contributions

Five out of seven semitrailers have been continuously overloaded. The average magnitude of overloading was around $6000 \mathrm{~kg}$ which represents $25 \%$ more than maximum allowed by Council Directive 96/53/EC. In some cases there has been even moments when the limit has been exceeded by more than $50 \%$, these loadings should be however considered more as extreme cases 
and should not be generalized with respect of the whole database. Considering further the five continuously overloaded semitrailers, it can be concluded that each trailer was overloaded nearly $30 \%$ of the operational time in average.

From the air spring readings we further distinguish three groups of semitrailer utilization modes apparently linked to the semitrailer type. These can be classified as follows:

- Group I. Trailers operating either empty or maximally loaded (\#1, \#2, \# 3, \#5, \#6) with the utilization ratio, described as loaded time/total operational time, near to $50 \%$.

- Group II. Trailers operating either empty or fully volumetrically loaded (\#7) where the ratio of utilization is also $50 \%$ but the operational weight depends on the type of transported cargo which vary.

- Group III. Trailers operating fully volumetrically loaded, with high utilization ratio being higher than $85 \%(\# 4)$.

The semitrailers in Group I (except semitrailer \#3) are mainly used in agriculture where the type of the cargo is diverse and varies in both structure and density. This eventually leads, as proven by the measurement, to frequent overloading which is being tolerated as the risk of being controlled on local public roads is relatively small. Contrary, the long haul semitrailer and livestock semitrailer were never overloaded due to strict regulation for transporting live animals as well as higher risk of the weight control when passing state borders on the highway.

Next, the results of the event registration, which monitor the quantitative loading pattern, are presented. The approach will be illustrated on the case of braking event and then only the final results for remaining events are provided. As input the event count spectrums were used. The spectrums are based on the deceleration magnitude in $\left[\mathrm{m} / \mathrm{s}^{2}\right]$ and were obtained by post processing routine that was described earlier.

As can be seen in Table 2 the counts of the braking events of semitrailers are being gradually sorted in eight bins according to the intensity level. Each bin has a span of $0.25 \mathrm{~m} / \mathrm{s}^{2}$ and its magnitude was determined basically with respect to the operational range and required resolution. Although differences between different semitrailers can be seen one can clearly observe a degrading relation between the intensity and the occurrence. In the last column of the Table 2, the events are summed among all semitrailers for the complete measurement time and subsequently plotted in Fig. 13a as a blue solid line.

There have been several attempts to reproduce the measurement results by the regression line using various mathematic fitting techniques. The emphasis was on the accuracy of the estimate, however with limited use of parameters to avoid for example complex polynomial models. These models might be very accurate but also rather difficult to interpret due influence of numerous parameters. The final regression trend line was determined by the exponential fit. This empirical model proved to have the best fit with measurement data and is depicted as red dotted line on Fig. 13b. Its equation is displayed next to the graph together with the coefficient of determination $R^{2}$, used for regression assessment. The value of the coefficient of determination, which is being widely used in statistics, gives qualitative information about the accuracy of the trend line to the original data. The general expression of the regression model trend line could be thus written in from:

$$
y=T \cdot D \cdot e^{S \cdot x}
$$

where: $y$ - number of events [-]; $x$ - intensity level of events $\left[\mathrm{m} / \mathrm{s}^{2}\right] ; t$ - time duration [hours]; $S, D$ - coefficients.

The role of coefficients $D$ and $S$ was further identified based on the calculations listed in the Table 3 for all measured semitrailers. For the determination of the $D$ coefficient we normalized the original number T.D, as estimated by the regression fit, by the duration of the test $\mathrm{T}$ in the third column of Table 3 . Subsequently we disregarded maximal and minimal value from the resulting array of $D$ coefficients. It resulted in rather consistent values of the $D$ coefficient indicating similar loading pattern of 5 semitrailers no matter on the length of test period.

Table 2. Braking event registration

\begin{tabular}{c|cccccccc}
\hline \multirow{2}{*}{ Level } & \multirow{7}{*}{ Trailer } & \multicolumn{7}{c}{ Braking event } \\
\cline { 2 - 9 } & $\# 1$ & $\# 2$ & $\# 3$ & $\# 4$ & $\# 5$ & $\# 6$ & $\# 7$ & Total number of events \\
\hline I & 3421 & 6289 & 9874 & 10806 & 7970 & 4828 & 7286 & 50474 \\
\hline II & 1275 & 3821 & 3278 & 4551 & 2545 & 3344 & 2999 & 21813 \\
\hline III & 769 & 2116 & 1409 & 2365 & 839 & 2046 & 1359 & 10903 \\
\hline IV & 368 & 1058 & 484 & 1091 & 300 & 1210 & 332 & 4833 \\
\hline V & 242 & 443 & 328 & 622 & 90 & 555 & 127 & 2407 \\
\hline VI & 200 & 110 & 124 & 297 & 59 & 348 & 50 & 1188 \\
\hline VII & 63 & 48 & 71 & 134 & 23 & 192 & 54 & 585 \\
\hline VIII & 24 & 28 & 19 & 39 & 5 & 74 & 7 & 196
\end{tabular}


a)

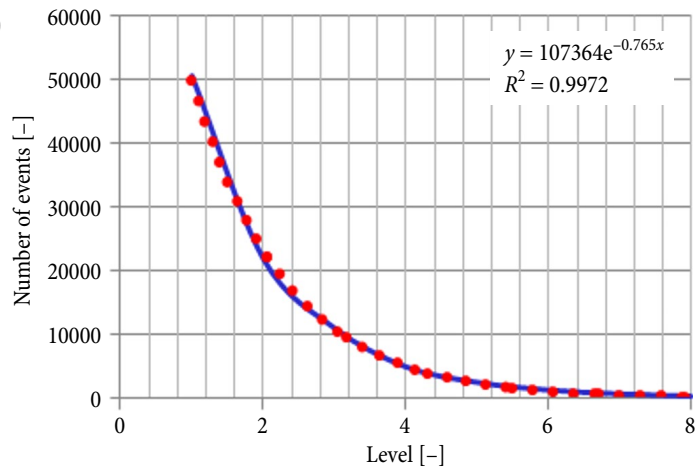

c)

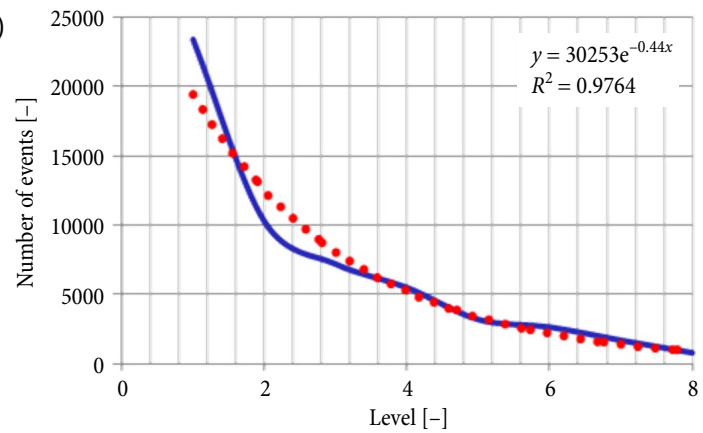

e)

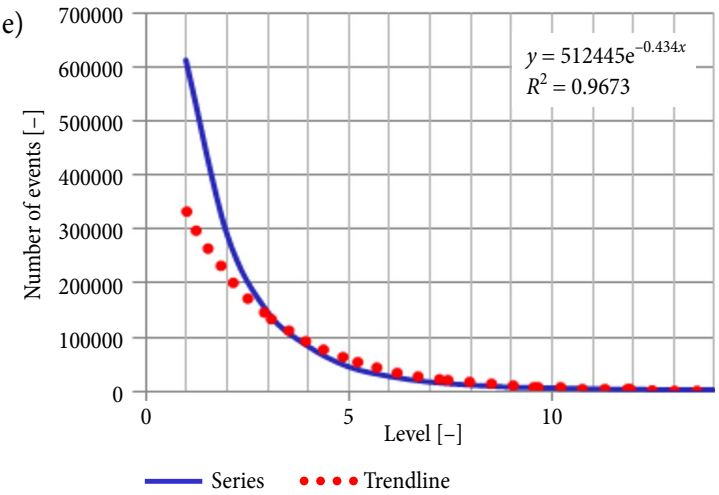

b)

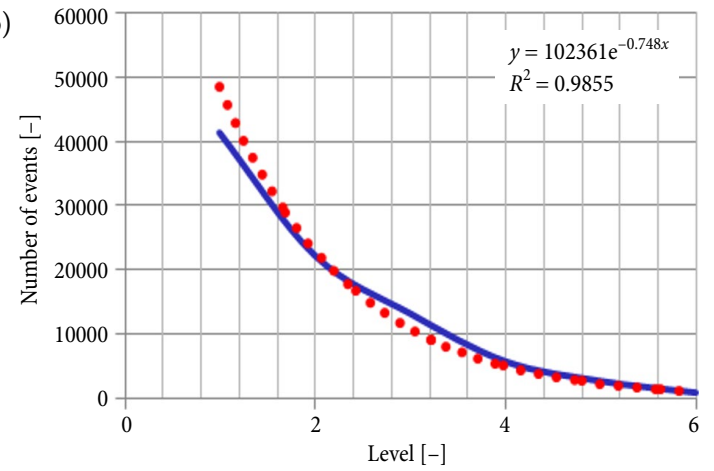

d)

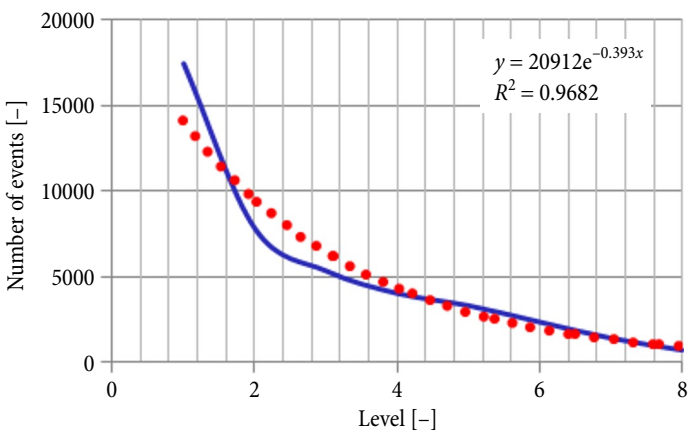

f)

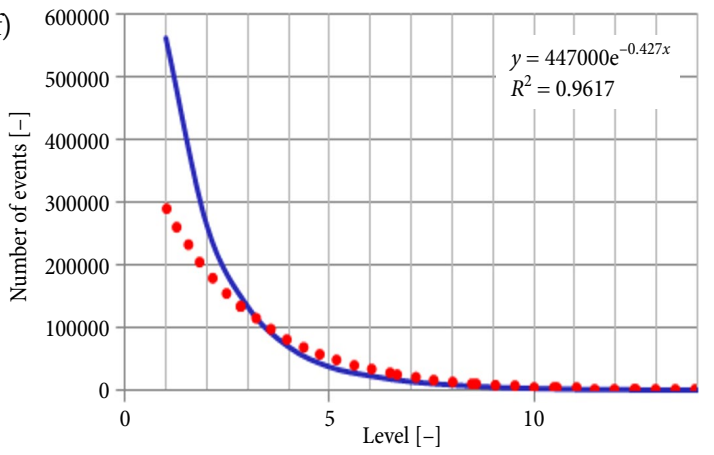

Fig. 13. Results: $\mathrm{a}$ - braking; $\mathrm{b}$ - acceleration; $\mathrm{c}$ - right cornering; $\mathrm{d}$ - left cornering; $\mathrm{e}$ - heaving up; $\mathrm{f}$ - heaving down

Table 3. Coefficients $S$ and $D$ for braking

\begin{tabular}{cccccc}
\hline Trailer \# & $D \cdot T$ & Test duration, $T$ [hours] & Coefficient $D$ & Coefficient of determination, $R^{2}$ & Coefficient $S$ \\
\hline 1 & 5671 & 60 & 94.52 & 0.9737 & -0.645 \\
\hline 2 & 20463 & 270 & 75.79 & 0.9822 & -0.828 \\
\hline 3 & 14313 & 110 & 130.11 & 0.99 & -0.841 \\
\hline 4 & 23441 & 210 & 111.62 & 0.991 & -0.759 \\
\hline 5 & 18769 & 137.5 & 136.50 & 0.9916 & -1 \\
\hline 6 & 10830 & 90 & 120.33 & 0.988 & -0.59 \\
\hline 7 & 18769 & 153 & 122.67 & 0.975 & -0.94 \\
\hline
\end{tabular}

The $D$ coefficient can be then understood as quantitative characteristics of the occurrence for each particular event and is generally influenced by type of the road (highway vs. local road) and driving style. Coefficient $S$ showed also consistency in results; however is not apparently time related. The values of $S$ prescribe an intensity distribution related to each particular manoeuvre and varies according to the event. The averaged values of $S$ coefficient for all registered events are listed in Table 4. Is should be noted that, coefficient $S$, as well as $D$ coefficient, is influenced by particular driving style of the driver. As the acceleration span of the bin has been kept equal for all events $\left(0.25 \mathrm{~m} / \mathrm{s}^{2}\right)$, the number of levels for particular event varies in order to cover acceleration 
Table 4. S coefficient for all events

\begin{tabular}{ccccccc}
\hline Event & Braking & Acceleration & Left curve & Right curve & Heave up & Heave down \\
\hline Coefficient $S$ & -0.765 & -0.748 & -0.393 & -0.44 & -0.434 & -0.427 \\
\hline
\end{tabular}

bandwidth of the interest corresponding to normal operation. The number of bins and the bandwidth for each event are listed below:

- acceleration $0.5 \div 2 \mathrm{~m} / \mathrm{s}^{2}$ (6 bins);

- braking $0.5 \div 2.5 \mathrm{~m} / \mathrm{s}^{2}$ ( 8 bins);

- right cornering $0.5 \div 2.5 \mathrm{~m} / \mathrm{s}^{2}$ (8 bins);

- left cornering $0.5 \div 2.5 \mathrm{~m} / \mathrm{s}^{2}$ (8 bins);

- heave up $1 \div 4.5 \mathrm{~m} / \mathrm{s}^{2}$ (14 bins);

- heave down $1 \div 4.5 \mathrm{~m} / \mathrm{s}^{2}$ ( 14 bins).

The events that have lower intensity than the bandwidth threshold i.e. $0.5 \mathrm{~m} / \mathrm{s}^{2}$ (or $1 \mathrm{~m} / \mathrm{s}^{2}$ for vertical events) were disregarded due to minor contribution to the fatigue life. Contrary the events, which were registered above the bandwidth threshold, were for each semitrailer very irregular and strongly dependent on the way the semitrailer is employed. Finalized models together with measurements data for remaining events are plot in Fig. 13c-f.

One can see that the fit for other manoeuvres achieved reasonable accuracy except for lower levels of heave up and heave down which are however considered to have less significance due to its low intensity. In case of cornering clear breakpoint is observed on the second level where frequency of events significantly increases. This can be explained by the preferred infrastructure design where the intention is to minimize the amount of sharp corners due to the safety issues.

As a next step we analysed the combined load matrix, which allowed the quantification of collective load patterns obtained from the simultaneous post processing of three semitrailer body accelerations. Though the most frequent combination was identified a soft braking accompanied with soft cornering, the results for particular vehicles were very diverse and no general statement could be drawn. To judge the overall combined loading, the time fractions of loading patterns when absolute value of at least one of the accelerations exceeded $1 \mathrm{~m} / \mathrm{s}^{2}$ have been summed. The results are listed in Table 5 as percentage of the total driving time for each semitrailer. The most influencing factor appeared to be quality of the road which is linked with the manner how the semitrailer is being employed. Thus long haul semitrailer together with livestock one became again least loaded contrary to semitrailers operating in agriculture or civil engineering. Though the approximation of the load history by exponential functions seems to be simplistic, it shows very good match with measured results. Furthermore is easy to use for which is feasible for direct application in semitrailer industry.

Table 5. Percentage of the driving time under combined load

\begin{tabular}{lccccccc}
\hline Trailer \# & 1 & 2 & 3 & 4 & 5 & 6 & 7 \\
\hline $\begin{array}{l}\text { Drive } \\
\text { time [\%] }\end{array}$ & 4.18 & 9.84 & 8.41 & 2.25 & 4.15 & 9.71 & 2.44 \\
\hline
\end{tabular}

\section{Conclusions}

The real life loading conditions for a range of different trailer types were identified by means of an extensive test campaign. The vast amount of road data (forty thousand kilometres) was collected from six European countries over more than one thousand hours. The data were interpreted automatically by different signal processing algorithms, which were developed. Post processed results lead to following conclusions:

- the intensity and the occurrence in time of one of six events can be predicted by empirical model employing the exponential function with the coefficients that were described;

- the most frequent combined (multi-axial) loading pattern is the soft cornering with soft braking;

- semitrailers were overloaded very frequently, five out of seven vehicles were continuously overloaded in average $30 \%$ of the time;

- three main groups of the semitrailer load utilization modes were identified.

Furthermore an intelligent software system with graphical user interface that enables the automatic generation of the multibody simulation models for a wide variety of trailer configurations was developed. Both the vehicle dynamics behaviour and the tyre forces calculated by the models were validated against the test data for a variety of manoeuvres and different vehicle configurations. Either the validated multibody dynamics models or the simplified model approach presented earlier by Pauwelussen et al. (2010) can be used in combination with synchronized measurement data to create the realistic loading conditions for fatigue life calculations.

Obtained realistic load spectra together with readings from the strain gauges will be used as an input to follow-up project named LIFE (Life Fatigue Assessment). The ultimate goal of the project is to create and validate FEM models which enable optimalisation of critical spots and welds of the semitrailers. The emphasis will be put on employment of new connection techniques, such as for example bolting as well as use of different materials. The output should then lead to optimized light weight design of semitrailers, which is nowadays strongly required from the commercial transport sector.

\section{References}

Abramson, H. N. (Eds.). 1966. The Dynamic Behavior of Liquids in Moving Containers. Scientific and Technical Information Division, National Aeronautics and Space Administration. Washington. $467 \mathrm{p}$.

Badireddi, V. 2007. Tilting Risk for Articulated Vehicles in Case of a Moving Pay Load: Diploma Thesis. HAN University.

Bishop, N.; Kerr, S.; Caserio, A. 1995. Using MSC.Fatigue to estimate the fatigue damage caused to vibrating automotive components, in 1999 MSC Worldwide Automotive Confer- 
ence, 20-22 September 1999, Munich, Germany. 7 p. Available from Internet: http://web.mscsoftware.com/support/ library/conf/auto99/p03899.pdf

Breytenbach, B.; Els, P. S. 2011. Optimal vehicle suspension characteristics for increased structural fatigue life, Journal of Terramechanics 48(6): 397-408. http://dx.doi.org/10.1016/j.jterra.2011.09.004

Cao, D.; Song, X.; Ahmadian, M. 2011. Editors' perspectives: road vehicle suspension design, dynamics, and control, Vehicle System Dynamics 49(1-2): 3-28. http://dx.doi.org/10.1080/00423114.2010.532223

Chatzikomis, C. I.; Spentzas, K. N. 2009. A path-following driver model with longitudinal and lateral control of vehicle's motion, Forschung im Ingenieurwesen 73(4): 257-266. http://dx.doi.org/10.1007/s10010-009-0112-5

Council Directive 96/53/EC of 25 July 1996 Laying Down for Certain Road Vehicles Circulating within the Community the Maximum Authorized Dimensions in National and International Traffic and the Maximum Authorized Weights in International Traffic. 17 p. Available from Internet: http:// eur-lex.europa.eu/legal-content/EN/TXT/PDF/?uri=CELE $\mathrm{X}: 31996$ L0053\&from $=\mathrm{EN}$

Crosheck, J. E. 2001. The integration of analysis and test for full vehicle structural durability, in Proceedings of the $3 \mathrm{rd}$ Simulation Based Acquisition Conference, 15-17 May 2001, Springfield, Virginia.

Dietz, S.; Netter, H.; Sachau, D. 1998. Fatigue life prediction of a railway bogie under dynamic loads through simulation, Vehicle System Dynamics 29(6): 385-402. http://dx.doi.org/10.1080/00423119808969381

Dodge, F. T. 2000. The New Dynamic Behaviour of Liquids in Moving Containers: Technical Report. Southwest Research Institute, San Antonio, Texas. 195 p.

Falkner, A.; Reinalter, W. 2006. Consistent vehicle model for determining the design envelope, ride comfort and component load, Vehicle System Dynamics 44(1): 468-478. http://dx.doi.org/10.1080/00423110600874453

Fermér, M.; McInally, G.; Sandin, G. 1999. Fatigue life analysis of Volvo S80 bi-fuel, in 1999 MSC Worldwide Automotive Conference, 20-22 September 1999, Munich, Germany. 7 p. Available from Internet: http://web.mscsoftware.com/support/library/conf/auto99/p00499.pdf

Gombor, B. 2005. Dynamic analysis of a bus body frame: determination of the loads and stresses, Vehicle System Dynamics 43(11): 807-822.

http://dx.doi.org/10.1080/00423110500273400

He, Y.; McPhee, J. 2005. A design methodology for mechatronic vehicles: application of multidisciplinary optimization, multibody dynamics and genetic algorithms, Vehicle System Dynamics 43(10): 697-733. http://dx.doi.org/10.1080/00423110500151077

Kural, K.; Prati, A.; Besselink, I.; Pauwelussen, J.; Nijmeijer, H. 2013. Validation of longer and heavier vehicle combination simulation models, SAE Technical Paper 2013-01-2369. http://dx.doi.org/10.4271/2013-01-2369

Lee, D.-C.; Han, C.-S. 2009. CAE (computer aided engineering) driven durability model verification for the automotive structure development, Finite Elements in Analysis and Design 45(5): 324-332. http://dx.doi.org/10.1016/j.finel.2008.10.004

Lee, Y.-L.; Raymond, M. N.; Villaire, M. A. 1995. Durability design process of a vehicle suspension component, Journal of Testing and Evaluation 23(5): 354-363.

http://dx.doi.org/10.1520/JTE11405J
Lin, S.-H.; Cheng, C. G.; Liao, C. Y.; Chang, J.-M.; Wu, Y. M. 2006. Experiments and CAE Analyses for suspension under durability road load conditions, SAE Technical Paper 2006-01-1624. http://dx.doi.org/10.4271/2006-01-1624

Matsuishi, M.; Endo, T. 1968. Fatigue of Metals Subjected to Varying Stress. Japan Society of. Mechanical Engineers, Fukuoka, Japan.

McCullough, M. 2008. A comparison of tire-obstacle force models used in multi-body dynamics simulations, in $A n$ nual Technical Meeting of the Institute of Environmental Sciences \& Technology (ESTECH 2008), 4-7 May 2008, Bloomingdale, Illinois, USA, Vol. 2, 760-820.

Morel, A.; Bignonnet, A.; Germain, G.; Morel, F. 2010. Teaching durability in automotive applications using a reliability approach, International Journal on Interactive Design and Manufacturing 4(4): 281-287. http://dx.doi.org/10.1007/s12008-010-0110-8

Pacejka, H. 2012. Tire and Vehicle Dynamics. 3rd edition. Butterworth-Heinemann. $672 \mathrm{p}$.

Pauwelussen, J. P.; Visscher, J.; Merts, M.; Horn, R. 2010. An integrated testing and model based design approach for semi-trailer weight reduction, in HVTT11: International Heavy Vehicle Symposium: Balancing Competing Needs in Heavy Vehicle Transport Technology, 14-17 March 2010, Melbourne, Australia. 9 p. (CD).

Sharp, R. S.; Crolla, D. A. 1987. Road vehicle suspension system design - a review, Vehicle System Dynamics 16(3): 167-192. http://dx.doi.org/10.1080/00423118708968877

TNO Automotive. 2008. Mf-Tyre \& Mf-Swift 6.1. User Manual 2008. The Netherlands. 35 p.

Wang, D.-F.; Cheng, C.; Qin, M.; Liu, Z.-W. 2008. Rigid-elastic coupling modelling of air suspension and fatigue life prediction of its key part for heavy-duty truck, International Journal of Vehicle Design 47(1/2/3/4): 305-317. http://dx.doi.org/10.1504/IJVD.2008.020893

Zeiler, T. A. 2002. Use of structural dynamic and fatigue sensitivity derivatives in an automotive design optimization, Structural and Multidisciplinary Optimization 23(5): 390397. http://dx.doi.org/10.1007/s00158-002-0199-x

Zeiler, T. A.; Barkey, M. E. 2001. Design sensitivities of fatigue performance and structural dynamic response in an automotive application, Structural and Multidisciplinary Optimization 21(4): 309-315. http://dx.doi.org/10.1007/PL00013278

Zhang, Y.; Tang, A.; Palmer, T.; Hazard, C. 1999. Virtual proving ground - an integrated technology for full vehicle analysis and simulation, International Journal of Vehicle Design 21(4-5): 450-470. http://dx.doi.org/10.1504/IJVD.1999.005596 